\title{
Antrenör Pedagojik Yeterlik Ölçeğinin Türk Kültürüne Uyarlanması ve Genç Sporcuların Algılarına Göre Antrenörlerin Pedagojik Yeterliklerinin İncelenmesi
}

\author{
Adaptation of Trainers' Pedagogical Competencies Scale to Turkish Culture and \\ Examination of Trainers' Pedagogical Competencies According to Perceptions of
} Young Athletes

${ }^{1}$ Erkan Faruk ŞİRIN

${ }^{2}$ Ali SEVILMİŞ

${ }^{1}$ Selçuk Üniversitesi, Spor Bilimleri Fakültesi, Spor Yöneticiliği Bölümü, Konya

${ }^{2}$ Karamanoğlu

Üniversitesi, BESYO, Mehmetbey Yöneticiliği bölümü, KARAMAN

\section{Yazışma Adresi \\ Corresponding Address:}

Arş. Gör. Dr. Ali SEVİLMİŞ

ORCID: 0000-0001-8338-5927

Karamanoğlu Mehmetbey Üniversitesi /BESYO / Spor Yöneticiliği Bölümü

E-posta: alisevilmis@kmu.edu.tr

\section{ÖZ}

Bu çalışmanın amacı, Zetter (2008) tarafından geliştirilen Genç Sporcularda Antrenör Pedagojik Yeterlik Ölçeğinin (Pädagogischer Kompetenzmaßstab des Trainers im Nachwuchsleistungssport-PKTN) Türk genç sporcu örnekleminde uyarlanması ve farklı branşlarda yer alan genç sporcuların antrenörleri ile ilgili pedagojik yeterlik algılarının farklı değişkenlere göre incelenmesidir. Verilerin analizinde dil ve kapsam geçerliliği için Davis tekniği kullanılmıştır. Yapı geçerliliği için Doğrulayıcı Faktör Analizi (DFA) gruplar arası ortalama karşılaştırması için t testi ve tek yönlü varyans analizi teknikleri kullanılmıştır. Türkçe formun 4 farklı branşta yer alan toplam 461 genç sporcudan elde edilen veriler üzerinden yapılan doğrulayıcı faktör analizi sonuçları (X2 /sd =3,89 RMSEA=0.079) PKTN'nin empati ve dikkat, destek veya dayanışmanın engellenmesi, pozitif geri bildirim, sosyal destek, demokratik antrenman iklimi ve hedef odakl antrenman alt boyutlarından oluşan altı faktörlü modeli ile veri uyumunun desteklendiği görülmekle birlikte özgün ölçekle benzer bir yapıya sahip olduğu görülmüştür. Sonuç olarak PKTN’nin Türk sporcuların antrenörlerinin pedagojik algılarını ölçmede, ilgili araştırmalarda kullanılmaya uygun geçerli ve güvenilir bir ölçme aracı olduğu görülmüştür. Çalışmanın ikinci aşamasında ise yine 4 farklı branşta (hentbol, voleybol, futbol, basketbol) yer alan toplam 505 genç sporcuya ulaşılmış ve genç sporcuların cinsiyet, yaş ve antrenörün cinsiyeti değişkenlerine göre incelenmiştir. Analizler sonucunda genç sporcuların antrenörlerinin pedagojik yeterlikleri ile ilgili algılarında, empati ve dikkat, pozitif geri bildirim, sosyal destek ve hedef odaklı antrenman davranışlarında kadın sporcuların lehine anlamlı bir fark görülmüştür.

Anahtar Kelimeler: Genç sporcular, Antrenörün pedagojik yeterliliği, Geçerlik, Güvenilirlik, Ölçek uyarlaması

\section{ABSTRACT}

The aim of this study is to adapt Trainers' Pedagogical Competencies Scale in Young Athletes (Pädagogischer Kompetenzmaßstab des Trainers im Nachwuchsleistungssport-PKTN), developed by Zetter (2008), to the sample of Turkish young athletes and examine pedagogical competency perceptions of young athletes taking place in the different branches related to their trainers according to the different variables. Davis technique was used for language and content validity in the analysis of the data. Confirmatory factor analysis (CFA) was used for construct validity, and t-test and one-way analysis of variance were used for comparison between groups. In the results of the confirmative factor analysis (DFA) of Turkish form made though the data obtained from 461 young athletes taking place in 4 different branches (X2 /sd =3,89 RMSEA $=0.079$ ), although data compliance with 6-factors model of PKTN consisting of the sub-dimensions of "empathy and attention", "hindering support or solidarity", "positive feedback", "social support", "democratic training climate", and" targetoriented training" is seen to be supported, it is seen that it has a similar structure to original scale. As a result, it is seen that PRTN is a valid and reliable measuring scale that is suitable for using in the relevant studies in measuring the pedagogical perceptions of Turkish athletes. In the second stage of the study, 505 young athletes taking place again in 4 different branches were reached, and young athletes were examined according to the variables of gender, age and gender of trainers. As a result of analyses, in the perceptions of young athletes related to pedagogical competencies of their trainers, a significant difference was seen in favor of the female athletes in their behavior related to empathy and attention, positive feedback, social support, and target-oriented training.

Keywords: Young athletes, Pedagogical competency of trainer, Validity, Reliability, Scale adaptation 


\section{GíRIŞ}

Gerek bireysel sporlarda gerek takım sporlarında bir sporcunun başarısı sadece yeteneğinden gelen özelliklere ve çalışma azmine bağlı olmadığı gibi antrenörün tek görevi de antrenörlük yaptığı spor branşının teknik, taktik yeterliliklerini kazandırmak değildir. Kuşkusuz, antrenörün kaçınılmaz rollerinden birisi pedagojik özelliğidir (Pawlenka, 2004). Yani her antrenör bir eğitmendir (Krüger, 1989). Eğitim denildiğinde gelişimin sağlanması için planlı bir destekleme anlaşılmaktadır. Antrenörler için ilk amaç bu olmasa da daha küçük yaşlardaki sporcular ve genç sporcular için antrenörün pedagojik özelliği oldukça önemlidir (Kurz, 1988). Spor pedagojisi, genel pedagojinin özel bir disiplini olarak tanımlamaktadır. Tinning (2012) "Spor pedagojisinin, aktörler ve hedeflenen insan hareketini eğitme ve öğretme eylemlerinden oluştuğunu" belirtmiştir. Spor pedagojisi, yetişkin ve gençlerin spor ve beden eğitimi ile ilgili eğitim biçimleri, kişisel gelişim için sporun ve beden eğitiminin önemi ve birey ile spor ve fiziksel çevre arasındaki ilişki ile ilgili bir disiplin olarak tanımlanabilir. Pedagoji bir antrenörün nasıl öğreteceğine ilişkin olup; sporcuları tanıma, öğrenme yöntemleri, antrenmanlarla ve genel yaşamla ilgili kurallar ve normlar vb. bilgi ve becerileri kapsar. Burada antrenör hem eğitim veren bir öğreticidir hem de model olarak sporcularının sosyal davranışlarını, ilgi alanlarını, değerlerini ve bilinçlerini etkiler.

Antrenörlerin karmaşık öğrenme süreçlerindeki rolleri bir eğitimci olarak özel pedagojik amaçlara sahip olsalar da, asıl önemli görülen konu sporcularının kişiliklerinin gelişiminde sorumluluk sahibi olmalarıdır. Antrenörlerin sorumlu oldukları sporcuların problemleri ile ilgilenmeleri sporcuların gelişiminde kritik bir öneme sahiptir (Zetter, 2008). Özellikle sporcularının hayatlarında güçlü bir sosyal etkiye sahip olan antrenörler, sporda bir sosyalleşme ajanı olarak görülmektedir (Varga ve diğ., 2018). Holt ve diğ. (2011) sosyalleşmenin spor yoluyla olumlu etkisinin sporcuların farklı insanlarla iletişiminde ve işbirliğinde fark edildiğini belirtmiştir. Bu nedenle, sporcuların yaşları ne olursa olsun, antrenörler sadece sporcuların performanslarının gelişiminde değil, aynı zamanda karakterlerinin gelişiminde de sosyalleşme aracı olarak önemli bir rol oynamaktadır. Bununla birlikte, çocukluk ve gençlik ileri düzeyde sosyalleşme dönemleri olduğundan, çocukları ve ergenleri eğiten antrenörlerin sorumluluğu onlara sosyal normları, değerleri ve davranış kalıplarını iletmektir (Varga ve diğ., 2018).

Bir pedagog ve psikolog özelliği bağlamında antrenörlerin, genç sporcularla ilgili onları sadece antrenman yaptırma özelliği dışında ev, okul ve aile gibi diğer yaşam alanlarıyla ilişkisi olan bir kişilik olduklarının ve sporcularının yaşam alanlarını, gelişimlerini etkileyen bir birey olduklarını kabul etmesi gerekir. Bu yüzden antrenör "ben sadece salonda antrenmanımı yaparım" "ben sadece sorumlu olduğum branşı veririm" "sporcu dışarıda ne yaparsa yapsın beni ilgilendirmez" diyemez (Baumann, 2016). Başarılı antrenörlük araştırmalarında ilişkiler sporcunun peformans ve psikososyal gelişiminde büyük öneme sahiptir (Jowett ve Cockerill, 2002).

İlgili literatür incelendiğinde, antrenör ve sporcu etkileşimindeki bu dinamik sürecin çoğunlukla liderlik kavramı üzerinde yapılandığı görülmüştür (Chelladurai, 1993; Chelladurai ve Riemer, 1998). Fakat antrenör liderliğinin, sporcuantrenör ilişkisini tam anlamıyla açıklamadığı belirtilmiştir (Hinde, 1997) ve Smoll ve Smith (1989)'in belirttiği gibi antrenörlerin pedagojik ve psikolojik görev bilinci açısından önemli eksikliklerinin bulunduğu vurgulanmıştır.

Özellikle genç sporcuların okulla ya da çevre ile ilgili olan ilişkilerde sorunları olduğunda ya da spor dışında varoluşsal güvensizliğin ortaya çıkması durumunda, bu sorunlar spor ortamına (antrenör, sporcu ve antrenman ortamı) yansıması kaçınılmazdır. Spor ortamındaki antrenörlük bu nedenle başarılı bir eğitmen olmak için yeterli değildir. Sporda başarılı olmak isteniyorsa antrenör ve sporcu arasında pozitif bir ilişki olmalıdır (Baumann, 2016). Sporda antrenör ve sporcu etkileşiminin yüksek performans elde etmede önemli olduğu gerçeğinden yola çıkarak, spor pedagojisi konusundaki araştırmaların yetersiz kaldığı ve bu konuda daha ayrıntılı bir ölçme aracına gereksinim olduğu gözlenmektedir. Sporcu 
Antrenör Pedagojik Yeterlik Ölçeğinin Türk Kültürüne Uyarlanması ve Genç Sporcuların Algılarına Göre Antrenörlerin

Pedagojik Yeterliklerinin İncelenmesi

Adaptation of Trainers' Pedagogical Competencies Scale to Turkish Culture and Examination of Trainers' Pedagogical

Competencies According to Perceptions of Young Athletes

ve antrenör arasındaki ilişkinin farklı bir bakış açısından (yeni bir ölçme aracı) incelendiği bu çalışma ilgili literatüre katkıda bulunabilir ve başarılı ve etkili antrenörlük için ipuçları sağlayabilir.

Bu çalışmada Zetter (2008) tarafindan geliştirilen PKTN'nin Türkçe alan yazına katkı getireceği düşüncesiyle Türkçe 'ye uyarlanması amaçlanmıştır. PKTN empati ve dikkat, destek veya dayanışmanın engellenmesi, pozitif geri bildirim, sosyal destek, demokratik antrenman iklimi ve hedef odaklı antrenman davranışlarının sporcu antrenör ilişkisindeki pedagojik rolü genç sporcular örnekleminde ölçmek üzere geliştirilmiş bir ölçektir. Özellikle genç ve daha küçük yaşlardaki sporcular için Zetter (2008) tarafından vurgulanan antrenörün eğitim rolünün ötesinde pedagojik yeterliliği; kişilerarası ilişkileri biçimlendirmek, gençlerin kişilik gelişimlerine yardımcı olmak, onların iletişimini geliştirmek ve/veya etkileşimlerini daha uygun hale getirmek ve böylece kendi kendilerini yönetmelerini sağlamak, aynı zamanda gençlerden gelen eleştiriyi kabul ederken norm, değer ve teknikler verebilmek ve yapıcı bir şekilde kendi faaliyetlerine katkıda bulunmak, bir dayanışma duygusunun gelişimini teşvik etmek (antrenman grubu içinde), sporcuya vereceği anlayış ve duygusal destek ile hayal kırıklıkları, moral bozukluğu ile başa çıkmasını sağlamak ve sporcular için özellikle de sporun dışında hayatlarında sosyal destek kaynağı olmak şeklinde formüle etmiş̧tir.

İlgili literatür incelendiğinde, antrenör ve sporcu ilişkisi (Altıntaş ve diğ., 2012; Ekenci ve diğ., 2017; Selağzı ve Çepikkurt 2014), liderlik kavramı üzerinden antrenör davranışı (Güngörmüş ve diğ., 2008; Toros ve Tiryaki, 2006, Altıntaş ve diğ., 2012; Unutmaz ve Gençer, 2014; Filiz ve Demirhan 2017) gibi konularda ölçek uyarlama ve geliştirme çalışmalarına ulusal alan yazında rastlanırken, antrenörlerin pedagojik yeterlilik konusunda özelliklede genç sporcu örnekleminde araştırmaya rastlanmamıştır. Bu araştırmanın amacı, sporcu algılarına göre antrenörlerin pedagojik yeterliklerinin belirlenmesinde kullanılabilecek bir ölçeğin Türk kültürüne uyarlanması ve genç sporcuların antrenörleri ile ilgili pedagojik yeterlik algılarının belirlenen kişisel değiş̧enler açısından incelenmesidir.

\section{YÖNTEM}

Araştırmanın Birinci Aşaması: Uyarlama Çalışması: Araştırma, PKTN'nin Türk kültürüne uyarlanmasını ve genç sporcuların antrenör pedagojik algısının çeşitli değişkenlere göre incelenmesini içeren iki temel çalışma üzerinden kurgulanmıştır. İlk çalışma mevcut durumla ilgili betimsel bir yöntemle yapılan uyarlama çalışmasıdır. Anlık tarama modeline göre yürütülen ikinci çalışmada genç sporcuların algılarına göre antrenör pedagojik yeterlikleri belirlenmiştir. Bu araştırmalar (anlık tarama) var olduğu şekliyle, belli bir zamanda mevcut durumun betimlenmesi amacıyla yürütülen çalışmalar olarak tanımlanmaktadır (Büyüköztürk, 2016).

Çeviri Süreci: Uyarlama çalışmasında öncelikle orijinal ölçeğin geliştirme çalışmasını yapan Hannes Zetter ile iletişime geçilmiş (e-posta yoluyla), ölçeğin genç sporcular seviyesinde Türkçe'ye uyarlanabilmesi için gerekli izin alınmış ve çeviri prosedürü başlamıştır. Ölçek uyarlaması konusunda yapılan akademik araştırmalarda kaynak dilden hedef dile yapılan çeviri süreci büyük önem arz etmektedir (Beaton ve diğ., 2000). Bu süreçte önemli nokta uyarlama yapılacak dil ve kültüre uygunluktur. Orijinal dili Almanca olan ölçeğin, Almanca formun Türkçeye çevrilmesinde sıklıkla kullanılan Brislin ve diğ., (1973) tarafindan önerilen beş aşamalı (ilk çeviri; ilk çeviriyi değerlendirme; geri çeviri; geri çeviriyi değerlendirme ve uzman görüşü) tekniği kullanılmıştır. Illk aşamada bir çeviri grubu belirli kriterler (Türkçeyi ve Almancayı iyi bilme, konuya hâkim olma) çerçevesinde oluşturulmuştur (Brislin ve diğ., 1973). Bu çeviri grubunda bu kriterlere sahip olan spor bilimi alanından iki ve psikolojik danışmanlık ve rehberlik alanından bir uzmanla bir grup oluşturulmuş ve ölçeğe ait maddelerin ve yanıt seçeneklerinin birbirlerinden bağımsız olarak çevirisi yapılmış ve değerlendirilmiş̧ir. Çeviriler Almancaya hâkim araştırmacı ve bir Almanca okutmanı ile beraber karşılaştırılmış ve maddeleri en iyi ifade ettiği varsayılan anlatımlar kabul edilmiştir. Üçüncü aşamada ölçme aracı tekrar farklı üç uzman 
(S.Ü. YADAM öğretim elemanı) tarafından Almanca 'ya geri çevrilmiştir. Dördüncü aşamada iki form arasında kavram, sözcük anlamı açısından eşitlikler karşılaştırma yapılarak kontrol edilmiş Türkçe formunun son haline karar verilmiştir. Üzerinde uzlaşılan Türkçe form, dil ve anlatım bakımından incelenmesi için beşinci ve son aşama olan aşamada bir Türk dili uzmanının (S.Ü. YADAM öğretim elemanı) görüşüne sunulmuş ve değerlendirmeleri 1şığında maddelerde gerekli düzenlemeler yapılarak ölçeğin nihai Türkçe formu oluşturulmuştur.

Türkçe form, özgün formda olduğu gibi, empati ve dikkat, destek veya dayanışmanın engellenmesi, pozitif geri bildirim, sosyal destek, demokratik antrenman iklimi ve hedef odaklı antrenman alt boyutlarından oluşan toplam 29 madde içermektedir. Maddeler için cevap seçenekleri orijinal ölçekte olduğu gibi 5'li likert tipi olup, "her zaman (5)”, “genellikle (4)", "bazen (3)", "nadiren (2)” ve "hiçbir zaman (1)” şeklinde yapılandırılmıştır. Her bir alt boyut için puan ortalamaları bağımsız bir şekilde hesaplanmaktadır.

Çalışma Grubu: PKTN'nin Türk kültürüne uyarlanması sürecinde, toplam üç farklı çalışma grubuna yer verilmiştir. Birinci çalışma grubu dil geçerliliği için, ikinci çalışma grubu yapı geçerliliği ve güvenirlilik analizleri için ve üçüncü çalışma grubu ise araştırmanın ikinci amacını gerçekleştirmek için genç sporcuların antrenörleri ile ilgili pedagojik yeterlik algılarının çeşitli değişkenlere göre incelenmesi için oluşturulmuştur.

Birinci çalışma grubunda kaynak dilden hedef dile yapılan çeviri sürecinde üç, geri çeviri sürecinde üç ve dil ve kapsam geçerliliğinin belirlenmesi amacıyla üç olmak üzere toplam 9 katılımcı yer almıştır.

İkinci çalışma grubunu PKTN'nin yapı geçerliği ve iç tutarlılık analizleri örneklemini Konya ve Karaman illerinden 14-17 yaşları arasında hentbol $(n=88)$, voleybol $(n=63)$, futbol $(n=256)$ ve basketbol $(n=54)$ branşlarından 33 kadın 428 erkek toplam 461 genç sporcu oluşturmuştur. Araştırmaya bu aşamada katılan genç sporcuların branş ve yaşlarına göre dağılımları Tablo 1 'de verilmiştir.

Tablo 1 . Deneme uygulamasına katılan genç sporcuların branș ve yașlarına göre dağılımı

\begin{tabular}{|c|c|c|c|c|c|}
\hline \multirow{2}{*}{ Branş } & \multicolumn{4}{|c|}{ Yaş } & \multirow[b]{2}{*}{ Toplam } \\
\hline & 14 yaş & 15 yaş & 16 yaş & 17 yaş & \\
\hline Hentbol & 24 & 23 & 6 & 35 & 88 \\
\hline Voleybol & 15 & 23 & 15 & 10 & 63 \\
\hline Futbol & 57 & 83 & 61 & 55 & 256 \\
\hline Basketbol & 12 & 24 & 7 & 11 & 54 \\
\hline Toplam & 108 & 153 & 89 & 111 & 461 \\
\hline
\end{tabular}

PKTN'nin uyarlamasında sonra, araştırmanın ikinci aşaması olan genç sporcuların algılarına göre antrenör pedagojik yeterliklerinin belirlenmesi aşamasına geçilmiştir.

Verilerin toplanması: Araştırma verileri araştırmacılar tarafından ilgili şehirlere giderek antrenmanlar sonrası toplanmıştır. Çalışma grubunu oluşturan genç sporcularda gönüllülük esas alınmıştır. Sporcular ölçek ve yapılacak olan çalışma hakkında bilgilendirilmiştir. Ölçek uygulaması her bir sporcu tarafından yaklaşık 10 dakikada tamamlanmıştır. PKTN'nin uyarlamasında ve sporcuların algılarına göre antrenörlerin pedagojik yeterliklerinin incelenmesi için aynı yöntemle veri toplanmıştır.

Verilerin Analizi: Dil ve kapsam geçerliliği çalışması kapsamında, uzmanların verdiği görüşler kapsam geçerlilik oranı (KGO) Davis tekniği kullanılarak, uzman görüşleri arasındaki farklılık Kendall Uyuşum Katsayısı (W) testi sonuçları ile incelenmiştir. Antrenör Pedagojik Yeterlik Ölçeğinin yapı geçerliği doğrulayıcı faktör analizi (DFA) ile verinin oluşturulan yapı ile ne derece uyum sağladığını değerlendirmek için, ki-kare ( $\chi 2)$ uyumu, $\chi 2 /$ sd oranı, düzenlenmiş iyilik uyum indeksi (Adjusted Goodness of Fit Index, AGFI), iyilik uyum indeksi (Goodness of Fit Index, GFI), karşılaştırmalı uyum indeksi (Comparative Fit Index; CFI), normlaştırılmış uyum indeksi (Normed Fit Index, NFI), 
Antrenör Pedagojik Yeterlik Ölçeğinin Türk Kültürüne Uyarlanması ve Genç Sporcuların Algılarına Göre Antrenörlerin

Pedagojik Yeterliklerinin İncelenmesi

Adaptation of Trainers' Pedagogical Competencies Scale to Turkish Culture and Examination of Trainers' Pedagogical

Competencies According to Perceptions of Young Athletes

normlaştırılmamış uyum indeksi (Non-normed Fit Index, NNFI), göreli uyum indeksi (Relative Fit Index, RFI), fazlalık uyum indeksi (Incremental Fit Index, IFI) ve yaklaşık hataların ortalama karekökü (Root Mean Square Error of Approximation, RMSEA) uyum iyiliği indeksleri ve değerleri kullanılmıştır.

Araştırmanın İkinci Aşaması: Sporcuların Algılarına Göre Antrenörlerin Pedagojik Yeterliklerinin İncelenmesi: Araştırmanın ikinci çalışması kapsamında genç sporcuların antrenörleri ile ilgili pedagojik yeterlik algıları çeşitli değişkenlere göre incelenmiştir. Antrenör ve sporcuların minimum bir yıl birlikte çalışmaları göz önünde bulundurulmuştur. $\mathrm{Bu}$ incelemede birinci çalışmada geçerliği ve güvenirliği sınanmış PKTN'nin Türk kültürüne uyarlanmış formu kullanılmıştır.

Araştırma Grubu: Araştırmanın ikinci aşaması olan genç sporcuların algılarına göre antrenör pedagojik yeterliklerinin belirlenmesi aşamasına geçilmiştir. Bu kapsamda, Ankara, Konya ve Karaman ilinden 14-17 yaşları arasında hentbol $(\mathrm{n}=94)$, voleybol $(\mathrm{n}=100)$, futbol $(\mathrm{n}=249)$ ve basketbol $(\mathrm{n}=62)$ branşlarından 51 kadın, 454 erkek toplam 505 genç sporcu oluşturmuştur. İkinci aşamada ulaşılan genç sporcuların branş ve yaşlarına göre dağılımları Tablo 2'de verilmiştir.

Tablo 2. Asıl uygulamaya katılan genç sporcuların branş ve yaşlarına göre dağılımı

\begin{tabular}{|c|c|c|c|c|c|}
\hline \multirow{2}{*}{ Branş } & \multicolumn{4}{|c|}{ Yaş } & \multirow[b]{2}{*}{ Toplam } \\
\hline & 14 yaş & 15 yaş & 16 yaş & 17 yaş & \\
\hline Hentbol & 20 & 23 & 14 & 37 & 94 \\
\hline Voleybol & 25 & 27 & 26 & 22 & 100 \\
\hline Futbol & 45 & 71 & 68 & 65 & 249 \\
\hline Basketbol & 10 & 21 & 12 & 19 & 62 \\
\hline Toplam & 100 & 142 & 120 & 143 & 505 \\
\hline
\end{tabular}

Verilerin Analizi: Sporcuların algılarına göre antrenörlerin pedagojik yeterliklerinin incelenmesi amacıyla (parametrik tekniklerin varsayımlarının karşılandığı için) parametrik testler olan $t$ testi ve ANOVA kullanılmıştır. Ayrıca antrenörlerin pedagojik yeterlikleri ile yaş arasındaki ilişki Pearson Korelasyon Katsayısı ile hesaplanmıştır. Ayrıca ölçeğin iç tutarlılığı Cronbach $\alpha$ katsayısı ile incelenmiştir. Araştırmada veriler IBM SPSS 24.0 ve LISREL 8.8 programları kullanılarak analiz edilmiş ve anlamlılık düzeyi .05 olarak kabul edilmiş̧ir.

\section{BULGULAR}

Bu bölümde ilk önce PKTN'nin uyarlanması aşamalarına ilişkin bulgular yer almıştır. Bu aşamada sırası ile dil geçerliliği, PKTN'nin geçerlik ve güvenirliği ve esas uygulama bulguları verilmiştir.

Dil ve kapsam geçerliliği: Türkçe ve Almanca'yı ve iki kültürü de iyi bilen yeterli sporcuya ulaşılamadığı için "uzman kişiye danışmak" ya da "uzman görüşü” yöntemi kullanılmıştır. Türkçe form ve Almanca form, hem dil hem de kapsam geçerliğinin belirlenmesi amacıyla spor bilimleri alanında çalışan 3 öğretim elemanın (uzman) görüşüne sunulmuştur. Uzmanlar ölçek maddelerini uygunluklarına göre (uygun değil/1 puan, biraz uygun/2 puan, uygun ancak ufak değişiklikler gerekli/3 puan, çok uygun/4 puan) değerlendirmiştir. Uzmanların değerlendirmeleri kapsam geçerlilik oranı (KGO) Davis tekniği kullanılarak, değerlendirilmiştir. KGO’nın hesabında maddeleri "uygun" ve "çok uygun" olarak değerlendiren uzman sayısı toplam uzman sayısına bölünerek her maddeye ilişkin KGO hesaplanmıştır (Davis, 1992). Hesaplanan KGO değerinin 0.80 den yüksek olması uygun görülmektedir. Ölçek maddelerinin KGO değerlerinin 0.93 olduğu belirlenmiş ve ölçekte yer alan maddelerin tamamının uygun olduğu düşünülerek, ölçekten herhangi bir madde çıkarılmamıştır. Uzman görüşleri arasındaki farklııık Kendall Uyuşum Katsayısı (W) (Kendall Coefficient of Concordance) Testi sonuçları ile değerlendirilmiş̧tir (Kendall's W=0.121, $\mathrm{p}=0.137$ ). Kendall W; 0 “uyumluluk yok" ile 1 "tam uyumluluk" aralığında değerlendirilirken, kapsam geçerliğinin olması için $\mathrm{p}>0.05$ 'ten olmalıdır. Test sonucuna 
göre uzman görüşleri arasında farklılık olmadığı, ölçeğin Türkçe formunun kültürel uygunluğu yönünden "bağımsız gözlemciler arası uyum” güvenilirliğinin, dil ve kapsam geçerliliği ölçütlerinin sağlandığını göstermektedir.

Yapı geçerliliği: PKTN'nin yapı geçerliliği için ölçeğin orijinalinde bulunan faktörlerin doğrulanması amacıyla Doğrulayıcı Faktör Analizi (DFA) yapılmıştır. Uyarlama çalışmalarında ve özellikle de farklı kültürlerde ve örneklemlerde geliştirilen ölçeklerde DFA, bir geçerlik belirleme yöntemi olarak kullanılmaktadır (Seçer, 2017). Sümer (2000) ve Çokluk ve diğ., (2014), göre DFA kuramsal bir temele dayanan önceki araştırmalarla tanımlanmış ve sınırlandırılmış bir yapının, bir model olarak doğrulanıp doğrulanmadığının değerlendirilmesidir.

Uyarlama çalışması gerçekleştirilen PKTN'nin, yedi madde bulunan Empati ve Dikkat (ED), sekiz madde bulunan Destek veya Dayanışmanın Engellenmesi (DDE), üç madde bulunan Pozitif Geri Bildirim (PGB), dört soru bulunan Sosyal Destek (SD), üç madde bulunan Demokratik Antrenman İklimi (DAİ) ve dört madde bulunan Hedef Odaklı Antrenman (HOA)'den oluşan 29 maddeli altı faktörlü bir ölçme aracı olduğu bilinmektedir (Zetter, 2008). Yapı geçerliği kapsamında, 461 genç sporcudan sağlanan veriler ile PKTN'de tahmin edilen altı faktörlü yapı arasındaki uyum DFA ile incelenmiştir.

PKTN'nın yapı geçerliğinin incelenmesinde öncelikle birinci düzey DFA sonrasında ikinci düzey DFA uygulanmıştır. PKTN'ne uygulanan birinci düzey DFA sonucunda ölçeğin 17. maddesi (bizlerden 'körü körüne' kurallara uymamızı ister) ve 24. maddesi (kötü sonuçlarda hatayı kendinde ve biz oyuncularda arar) için anlamlı $\mathrm{t}$ değerleri belirlenememiş ve bu maddelerle ilgili hata varyansının da $(1,00 ; 0,99)$ yüksek olduğu belirlenmiştir. Bu nedenle, 17. ve 24 . maddelerin ölçekten çıkarılmasına karar verilmiştir. İki maddesi çıkartılan PKTN'nin diğer maddelerinden elde edilen t değerlerinin 2.58'den büyük olması, .01 düzeyinde anlamlılığı göstermektedir (Kline, 2016). PKTN 'de yer alan maddelerin gizil değişkenlerle olan ilişkileri ile ilgili katsayıların (t değerlerinin) 2.58'den büyük ve 5.38 ile 18.57 arasında değiştiği görülmüştür. Diğer tüm maddelerin anlamlı (.01 düzeyinde) olduğu ve modelde yer alması uygun görülerek ikinci düzey DFA uygulanmıştır.

Uygulanan modelin yeterliğini belirlemek için pek çok uyum indeksi ve değerleri kullanılmasına rağmen bu çalışmada ki-kare $(\chi 2)$ uyumu, $\chi 2$ /sd oranı, düzenlenmiş iyilik uyum indeksi (AGFI), iyilik uyum indeksi (GFI), karşılaştırmalı uyum indeksi (CFI), normlaştırılmış uyum indeksi (NFI), normlaştırılmamış uyum indeksi (NNFI), göreli uyum indeksi (RFI), fazlalık uyum indeksi (IFI) ve yaklaşık hataların ortalama karekökü (RMSEA) uyum indeksleri ve değerleri incelenmiştir. Uygulanan modellerin sınır değerleri ve indeksleri ile birlikte, 17. ve 24. maddeler çıkarılmadan önce elde edilen değerler (DFA I) ve çıkarıldıktan sonra elde edilen değerler (DFA II) Tablo 3'de verilmiştir.

Tablo 3. Doğrulayıcı Faktör Analizi Sonuçları

\begin{tabular}{lccc}
\hline Indeks & Sınır Değerler & DFA I & DFA II \\
\hline $\mathbf{X}^{2} /$ Sd & Mükemmel $\leq 3 \leq \dot{\text { İyi } \leq 5}$ & 3.96 & 3.89 \\
\hline AGFI & Mükemmel $\geq .95 \geq$ İyi $\geq .90$ & 0.79 & 0.80 \\
\hline GFI & Mükemmel $\geq .95 \geq \dot{\text { İyi } \geq .90}$ & 0.82 & 0.84 \\
\hline CFI & Mükemmel $\geq .95 \geq$ İyi $\geq .90$ & 0.91 & 0.92 \\
\hline NFI & Mükemmel $\geq .95 \geq$ İyi $\geq .90$ & 0.88 & 0.90 \\
\hline NNFI & Mükemmel $\geq .95 \geq$ İyi $\geq .90$ & 0.90 & 0.91 \\
\hline RFI & Mükemmel $\geq .95 \geq$ İyi $\geq .90$ & 0.87 & 0.90 \\
\hline IFI & Mükemmel $\geq .95 \geq \dot{\text { İyi } \geq .90}$ & 0.91 & 0.92 \\
\hline RMSEA & Mükemmel $\leq .05 \leq$ İyi $\leq .08$ & 0.08 & 0.079 \\
\hline
\end{tabular}

DFA I ile maddeler çıkartılmadan önce test edilen modelin uyum indeksleri incelendiğinde Ki-Kare değerinin $(\chi 2=1438.21, \mathrm{~N}=461, \mathrm{sd}=362, \mathrm{p}<0.001)$ anlamlı olduğu görülmektedir. Diğer yandan örneklem büyüklüğ̈̈ne duyarlı olan 
Antrenör Pedagojik Yeterlik Ölçeğinin Türk Kültürüne Uyarlanması ve Genç Sporcuların Algılarına Göre Antrenörlerin

Pedagojik Yeterliklerinin İncelenmesi

Adaptation of Trainers' Pedagogical Competencies Scale to Turkish Culture and Examination of Trainers' Pedagogical

Competencies According to Perceptions of Young Athletes

$\chi 2$ test sonuçlarının anlamlı çıkma ihtimalini artabileceği belirtilmiş (Çokluk ve diğ., 2010) ve bu nedenle $\chi 2 /$ sd oranına bakılması tavsiye edilmiş̧tir (Sümer, 2000; Büyüköztürk ve diğ., 2004). DFA I'de $\chi 2 / s d$ oranı 3.96'dır. Kline (2005)'e göre $\chi 2 /$ sd oranının büyük örneklem guruplarında 3’ten daha küçük olması mükemmel; 5 'ten daha küçük olması da iyi uyumu işaret etmektedir. Bu doğrultuda $\chi 2 /$ sd oranının (3.96) iyi uyum sınırları dâhilinde yer aldığı görülmektedir. Tablo 3 incelendiğinde DFA I'de, CFI, NNFI ve IFI indekslerinin iyi uyumu gösterdiği ve RMSEA=0,08 düzeyinde olduğu görülmektedir. 17. ve 24. maddelerin çıkarılmasından sonra elde edilen DFA II incelendiğinde Ki-kare değerinin azaldığı ve $\chi 2=1203,20(\mathrm{~N}=462, \mathrm{sd}=309, \mathrm{p}=0,00)$ olarak değiştiği görülmüştür. Yeni $\chi 2 / \mathrm{sd}$ oranı 3,89 olarak hesaplanmış ve RMSEA=0,079 düzeyinde olduğu görülmüştür. DFA I'den elde edilen uyum değerlerinden farklı olarak DFA II'de NFI ve RFI indekslerinin iyi uyum sınırları dâhilinde yer aldığı görülmektedir. Analizler sonucunda CFI, NNFI ve IFI indekslerinde bir değişim görülmezken, NFI'nın 0.88 'den 0.90 'a ve RFI'nın ise 0.87 'den 0.90 'a çıkarak iyi uyum sınırları dâhilinde yer aldığı görülmektedir. $X^{2} / S d$ derecesinin iyi uyum (Kline, 2011) ; CFI, NFI, NNFI, RFI, IFI değerlerinin mükemmel (Baumgartner ve Homburg 1996, Bentler 1980; Bentler ve Bonet 1980) RMSEA değerinin iyi uyum (Browne ve Kudek 1993) gösterdiği tespit edilmiştir. Özellikle $\mathrm{X}^{2} / \mathrm{Sd}$ derecesinin manidar çıkması model uyumu için bir ölçüt kabul edilebilir (Kline,2011). Bu uyum indeksi değerleri ele alındığında, ölçeğin Türkçe formunun orijinal ölçekle mükemmel olmasa da, model-veri uyumunun sağlandığı ve iyi uyum (kabul edilebilir) sağladığı söylenilebilir. DFA sonucunda elde edilen standardize edilmiş katsayılar-yol diyagramı-Şekil 1'de verilmiştir.

Şekil 1 incelendiğinde, faktör yüklerinin "Empati ve Dikkat" alt boyutu için .55 ile .72 aralığında; "Destek ve Dayanışmanın Engellenmesi" alt boyutu için .27 ile .79 aralığında; "Pozitif Geri Bildirim" alt boyutu için .51 ile .61 aralığında; "Sosyal Destek" alt boyutu için .57 ile .68 aralığında; "Demokratik Antrenman İklimi" alt boyutu için .50 ile .74 aralığında; "Hedef Odaklı Antrenman" alt boyutu için ise .44 ile .62 aralığında değiştiği görülmektedir.

"Destek ve Dayanışmanın Engellenmesi" alt boyutundaki bir maddenin .27 faktör yüküne sahip olmasının kabul edilebilirliği T-değerlerinin anlamlılı̆̆ ile ilişkilidir. T- değeri 5.38 olarak tespit edilmiştir. T değerinin 3.58'den büyük olması bu maddenin kabul edilebilirliğini göstermektedir (Çelik ve Yılmaz, 2014). Bu durum yakınsak geçerliliğe kanıt olarak öne sürülebilir. Faktörler arasındaki korelasyon kestirimlerinin aşırı yüksek olmaması da bu modelin ayırt edici geçerliliğinin kanıtı olarak ifade edilebilir. 


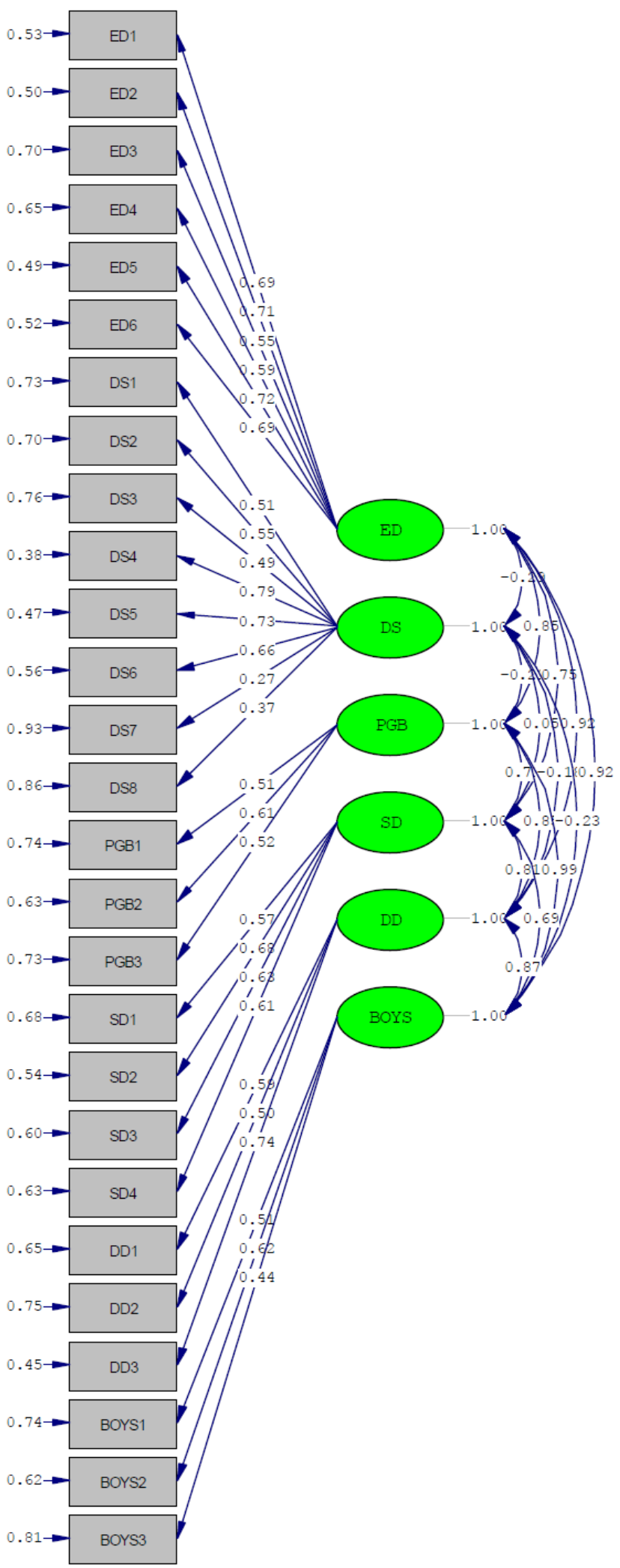

Chi-Square $=1203.20, \mathrm{df}=309, \mathrm{P}-\mathrm{value}=0.00000$, RMSEA $=0.079$

Şekil 1. PKTN yapısal modeli

Not: ED: Empati ve Dikkat, DDE: Destek ve Dayanışmanın Engellenmesi, PGB: Pozitif Geri Bildirim, SD: Sosyal Destek, DAİ: Demokratik Antrenman İklimi, HOA: Hedef Odaklı Antrenman 
Antrenör Pedagojik Yeterlik Ölçeğinin Türk Kültürüne Uyarlanması ve Genç Sporcuların Algılarına Göre Antrenörlerin

Pedagojik Yeterliklerinin İncelenmesi

Adaptation of Trainers' Pedagogical Competencies Scale to Turkish Culture and Examination of Trainers' Pedagogical

Competencies According to Perceptions of Young Athletes

Güvenilirlik: PKTN'nün güvenirlik analizinde boyutlara ait Cronbach alfa $(\alpha)$ değerleri incelenmiştir.

Tablo 4. PKTN'nin alt boyutlarının güvenirlik analizi sonuçları

\begin{tabular}{llcc}
\hline & \multicolumn{1}{c}{ Boyutlar } & Orijinal ölçek $(\boldsymbol{\alpha})$ & Uyarlanan Ölçek $(\boldsymbol{\alpha})$ \\
\hline ED & Empati ve Dikkat* & 0.78 & 0.80 \\
DDE & Destek veya Dayanışmanın Engellenmesi & 0.72 & 0.65 \\
PGB & Pozitif Geri Bildirim & 0.71 & 0.65 \\
SD & Sosyal Destek & 0.66 & 0.72 \\
DAI & Demokratik Antrenman İklimi & 0.65 & 0.63 \\
HOA & Hedef Odaklı Antrenman * & 0.49 & 0.62 \\
\hline
\end{tabular}

*DFA sonucunda bu alt boyutlarda ait bir madde ölçekten çıkarılmıştır.

Bundan sonraki aşamada PKTN'nin boyutlarına ait ortalama ve standart sapma değerleri ile PKTN'nin boyutları arasındaki korelasyonlar hesaplanmıştır.

Tablo 5. PKTN'nin alt boyutlarının ortalama ve standart sapmaları ile boyutlar arası korelasyon değerleri

\begin{tabular}{|c|c|c|c|c|c|c|c|c|c|}
\hline & Boyutlar & $\mathbf{X}$ & Ss & ED & DDE & PGB & SD & DAA & HOA \\
\hline ED & Empati ve Dikkat & 3.84 & .88 & - & & & & & \\
\hline DDE & Destek veya Dayanışmanın Engellenmesi & 2.83 & .70 & $-.141^{* *}$ & - & & & & \\
\hline PGB & Pozitif Geri Bildirim & 4.12 & .76 & $.581^{* *}$ & $-.099^{*}$ & - & & & \\
\hline SD & Sosyal Destek & 3.48 & 1.01 & $.583^{* *}$ & $-.158^{* * *}$ & $456^{* *}$ & - & & \\
\hline DAI & Demokratik Antrenman İklimi & 3.69 & .95 & $.666^{* *}$ & $-.181^{* *}$ & $.502^{* *}$ & $.581^{* *}$ & - & \\
\hline HOA & Hedef Odaklı Antrenman & 4.01 & .85 & $.603^{* *}$ & $.187^{* *}$ & $.540^{* *}$ & $.417^{* *}$ & $.485^{* *}$ & - \\
\hline
\end{tabular}

**p $<0.01$

Not: ED: Empati ve Dikkat DDE: Destek ve Dayanışmanın Engellenmesi PGB: Pozitif Geri Bildirim SD: Sosyal Destek DAİ: Demokratik Antrenman İklimi HOA: Hedef Odaklı Antrenman

Antrenör Pedagojik Yeterlik Ölçeğinin boyutları arasındaki korelasyon değerleri -0.09 ile 0.66 arasında değişmektedir. PKTN ölçeğinden alınan ortalama puanlar empati ve dikkat boyutu için 3,84 ( $\mathrm{Ss}=0.88)$, destek veya dayanışmanın engellenmesi boyutu için 2,83 ( $\mathrm{Ss}=0.70$ ), pozitif geri bildirim boyutu için 4.12 ( $\mathrm{Ss}=0.76$ ), sosyal destek boyutu için 3.48 ( $\mathrm{Ss}=1.01)$, demokratik antrenman iklimi boyutu için 3.69 ( $\mathrm{Ss}=0.95)$ ve hedef odaklı antrenman boyutu için 4.01 ( $\mathrm{Ss}=0.85$ )'dir. PKTN'nin Türkiye'de genç sporcular üzerinde yapılacak çalışmalarda kullanmak için uygun özelliklere sahip bir ölçek olduğu söylenilebilir.

Genç sporcuların cinsiyetine göre antrenörlerin pedagojik yeterlik algıları:

Tablo 6. PKTN alt boyut puanlarının cinsiyete göre karşılaştırılmasına ilişkin $t$ testi sonuçları

\begin{tabular}{|c|c|c|c|c|c|c|}
\hline Boyutlar & Cinsiyet & $\mathbf{N}$ & $\mathbf{X}$ & Ss & $t$ & $\mathbf{p}$ \\
\hline \multirow{2}{*}{ ED } & Kadın & 51 & 4.10 & .68 & \multirow{2}{*}{2.057} & \multirow{2}{*}{$.040^{*}$} \\
\hline & Erkek & 454 & 3.83 & .88 & & \\
\hline \multirow{2}{*}{ DDE } & Kadın & 51 & 2.82 & .66 & \multirow{2}{*}{-.185} & \multirow{2}{*}{.853} \\
\hline & Erkek & 454 & 2.84 & .71 & & \\
\hline \multirow{2}{*}{ PGB } & Kadın & 51 & 4.41 & .69 & \multirow{2}{*}{2.756} & \multirow{2}{*}{$.006^{*}$} \\
\hline & Erkek & 454 & 4.10 & .76 & & \\
\hline \multirow{2}{*}{ SD } & Kadın & 51 & 3.91 & .90 & \multirow{2}{*}{3.075} & \multirow{2}{*}{$.002^{*}$} \\
\hline & Erkek & 454 & $3, .46$ & 1.00 & & \\
\hline \multirow{2}{*}{ DAİ } & Kadın & 51 & 3.84 & .77 & \multirow{2}{*}{1.150} & \multirow{2}{*}{.251} \\
\hline & Erkek & 454 & 3.68 & .95 & & \\
\hline \multirow{2}{*}{ HOA } & Kadın & 51 & 4.47 & .65 & \multirow{2}{*}{3.918} & \multirow{2}{*}{$.000^{*}$} \\
\hline & Erkek & 454 & 3.98 & .85 & & \\
\hline
\end{tabular}

*p<0.05

Tablo 6'da görüldüğü gibi, genç sporcuların antrenörlerinin pedagojik yeterlikleri ile ilgili algılarının cinsiyet değişkenine göre anlamlı bir farklılık olup olmadığını belirlemek amacıyla gerçekleştirilen bağımsız grup t testi sonucunda empati ve dikkat $\left(\mathrm{t}_{(503)}=2.057 ; \mathrm{p}<.05\right)$, pozitif geri bildirim $\left(\mathrm{t}_{(503)}=2.756 ; \mathrm{p}<.05\right)$, sosyal destek $\left(\mathrm{t}_{(503)}=\right.$ 
3.075; $\mathrm{p}<.05)$ ve hedef odaklı antrenman $\left(\mathrm{t}_{(503)}=3.918 ; \mathrm{p}<.05\right)$ alt boyutlarında kadın sporcuların lehine anlamlı bir fark bulunmuştur. Destek veya dayanışmanın engellenmesi ve demokratik antrenman iklimi alt boyutlarındaki puan ortalaması farkının istatistiksel olarak anlamlı olmadığı bulunmuştur. Başka bir deyişle kadın ve erkek sporcuların antrenörlerin destek veya dayanışmanın engellenmesi ve demokratik antrenman iklimi pedagojik yeterlik algı düzeyleri benzerdir.

Tablo 7. PKTN alt boyut puanları ile yaş arasındaki ilişkiye yönelik korelasyon analizi sonuçları

\begin{tabular}{lccccccc}
\hline & & ED & DDE & PGB & SD & DAI & HOA \\
\cline { 3 - 8 } Yaş & $\mathrm{r}$ & $-.251^{* *}$ & $.193^{* *}$ & $-.123^{* *}$ & $-.164^{* *}$ & $-.206^{* *}$ & $-.107^{*}$ \\
& $\mathrm{p}$ & .000 & .000 & .006 & .000 & .000 & .017 \\
\hline
\end{tabular}
${ }^{*} \mathrm{p}<0.05,{ }^{* *} \mathrm{p}<0.01$

Tablo 7'de görüldüğü gibi sporcuların yaşı ile antrenör pedagojik yeterlik ölçeği empati ve dikkat $(\mathrm{r}=-.251 ; \mathrm{p}<.05)$, pozitif geri bildirim $(r=-.123 ; \mathrm{p}<.05)$, sosyal destek $(\mathrm{r}=-.164 ; \mathrm{p}<.05)$, demokratik antrenman iklimi $(\mathrm{r}=-.206$; $\mathrm{p}<$ $.05)$ ve hedef odaklı antrenman $(r=-.107 ; \mathrm{p}<.05)$ arasında negatif yönde, destek veya dayanışmanın engellenmesi $(\mathrm{r}=$ $.193 ; \mathrm{p}<.05)$ pozitif yönde anlamlı bir ilişki bulunmuştur. Bu bulgu sporcuların yaşı arttıkça antrenörün empati ve dikkat, pozitif geri bildirim, sosyal destek, demokratik antrenman iklimi ve hedef odaklı antrenman yeterlik algısının azaldığına işaret etmektedir. Ayrıca sporcuların yaşı arttıkça antrenörün destek veya dayanışmanın engellenmesi yeterlik algısının arttığına da işaret etmektedir.

Tablo 8. PKTN alt boyut puanlarının antrenör cinsiyete göre karşılaştırılmasına ilişkin t testi sonuçları

\begin{tabular}{|c|c|c|c|c|c|c|}
\hline Boyutlar & Antrenör Cinsiyeti & $\mathbf{N}$ & $\mathbf{X}$ & Ss & $\mathbf{t}$ & $\mathbf{p}$ \\
\hline \multirow{2}{*}{ ED } & Kadın Antrenör & 78 & 4.14 & .70 & \multirow{2}{*}{3.179} & \multirow{2}{*}{.002} \\
\hline & Erkek Antrenör & 427 & 3.81 & .88 & & \\
\hline \multirow{2}{*}{ DDE } & Kadın Antrenör & 78 & 2.69 & .64 & \multirow{2}{*}{-2.115} & \multirow{2}{*}{.035} \\
\hline & Erkek Antrenör & 427 & 2.87 & .71 & & \\
\hline \multirow{2}{*}{ PGB } & Kadin Antrenör & 78 & 4.35 & .68 & \multirow{2}{*}{2.712} & \multirow{2}{*}{.007} \\
\hline & Erkek Antrenör & 427 & 4.09 & .77 & & \\
\hline \multirow{2}{*}{ SD } & Kadın Antrenör & 78 & 3.92 & .86 & \multirow{2}{*}{4.042} & \multirow{2}{*}{.000} \\
\hline & Erkek Antrenör & 427 & 3.43 & 1.00 & & \\
\hline \multirow{2}{*}{ DAİ } & Kadın Antrenör & 78 & 3.90 & .72 & \multirow{2}{*}{2.073} & \multirow{2}{*}{.039} \\
\hline & Erkek Antrenör & 427 & 3.66 & .96 & & \\
\hline \multirow{2}{*}{$\mathrm{HOA}$} & Kadın Antrenör & 78 & 4.33 & .70 & \multirow{2}{*}{3.460} & \multirow{2}{*}{.001} \\
\hline & Erkek Antrenör & 427 & 3.97 & .86 & & \\
\hline
\end{tabular}

Tablo 8'da görüldüğü gibi, genç sporcuların antrenörlerinin pedagojik yeterlikleri ile ilgili algılarının antrenörlerin cinsiyeti değişkenine göre anlamlı bir farklılık olup olmadığını belirlemek amacıyla gerçekleştirilen bağımsız grup t testi sonucunda empati ve dikkat $\left(\mathrm{t}_{(503)}=3.179 ; \mathrm{p}<.05\right)$, pozitif geri bildirim $\left(\mathrm{t}_{(503)}=2.712 ; \mathrm{p}<.05\right)$, sosyal destek $\left(\mathrm{t}_{(503)}=\right.$ 4.042; $\mathrm{p}<.05)$ ve demokratik antrenman iklimi $\left(\mathrm{t}_{(503)}=2.073 ; \mathrm{p}<.05\right)$ ve hedef odaklı antrenman $\left(\mathrm{t}_{(503)}=3.460 ; \mathrm{p}<\right.$ .05) alt boyutlarında kadın antrenörleri olan sporcuların lehine, destek veya dayanışmanın engellenmesi ( $\mathrm{t}_{(503)}=-2.115$; $\mathrm{p}<.05$ ) erkek antrenörleri olan sporcuların lehine anlamlı bir fark bulunmuştur.

\section{TARTISMA, SONUÇ VE ÖNERILLER}

$\mathrm{Bu}$ araştırmada genç sporcuların antrenörleri ile ilgili pedagojik yeterlik algılarını belirlemeye yönelik olarak Zetter (2008) tarafından geliştirilen Genç Sporcularda Antrenör Pedagojik Yeterlik Ölçeğinin (PKTN) Türk Kültürüne uyarlanması amaçlanmıştır. Orijinal ölçekteki altı faktörlü yapı DFA ile test edilmiş ve güvenirlik katsayıları hesaplanmıştır. 
Antrenör Pedagojik Yeterlik Ölçeğinin Türk Kültürüne Uyarlanması ve Genç Sporcuların Algılarına Göre Antrenörlerin

Pedagojik Yeterliklerinin İncelenmesi

Adaptation of Trainers' Pedagogical Competencies Scale to Turkish Culture and Examination of Trainers' Pedagogical

Competencies According to Perceptions of Young Athletes

PKTN'nin Türk kültürüne uyarlanması aşamasında, Türkçe formun Almanca form ile dilsel geçerliğinin olduğu belirlenmiştir (KGO=0.93; Kendall's $\mathrm{W}=0.121, \mathrm{p}=0.137)$. PKTN'deki faktör isimleri orijinalinde olduğu gibi 1. Faktör "Empati ve Dikkat", 2. Faktör "Destek veya Dayanışmanın Engellenmesi”, 3. Faktör "Pozitif Geri Bildirim", 4. Faktör "Sosyal Destek", 5. Faktör "Demokratik Antrenman İklimi” ve 6. Faktör de "Hedef Odaklı Antrenman" olarak isimlendirilmiş̧ir. Faktörlerin iç tutarlılık katsayıları ise Empati ve Dikkat 0.80, Destek veya Dayanışmanın Engellenmesi 0.65, Pozitif Geri Bildirim 0.65, Sosyal Destek 0.72, Demokratik Antrenman İklimi 0,63 ve Hedef Odaklı Antrenman 0.62 olarak belirlenmiştir. Alpar (2010)'a göre bu bilgiler doğrultusunda iç tutarlılık katsayılarının kabul edilebilir sinırlarda olduğu görülmektedir.

PKTN'nin yapı geçerliliği için yapılan DFA sonucunda Ki-kare/sd derecesinin 3,89 olduğu tespit edilmiştir. Bu derecenin beşten küçük olması modelin veriye iyi uyum gösterdiği anlamına gelmektedir (Brown, 2005). Elde edilen uyum indeksleri incelendiğinde ise $\mathrm{CFI}=0.92 ; \mathrm{NFI}=0.90 ; \mathrm{NNFI}=0.91 ; \mathrm{RFI}=0.90 ; \mathrm{IFI}=0.92$ değerlerinin 0.90 ile 0.95 arasında yer alması iyi uyum sınırları dâhilinde yer aldığı görülmektedir (Hu ve Bentler, 1998). RMSEA değerinin 0,079 olarak tespit edilmesi bu değerin kabul edilebilir düzeyde olduğu söylenebilir (Browne ve Cudeck, 1993).

İlgili literatür incelendiğinde Güngörmüş ve diğ., (2008)'nin Sporda Liderlik Ölçeği (LSS) “Sporcuların Antrenörün Davranışlarını Algılaması” versiyonunda yapısal geçerlilik için açıklayıcı faktör analizi (AFA) kullandığı görülmüştür. Unutmaz ve Gençer (2014) SLÖ-SADA ölçeğini yapısal geçerliği DFA sonuçlarında Ki-kare/sd derecesini 3,61 olarak CFI değerini 0.86 , GFI değeri 0.84, IFI değerini 0.86 , NNFI değerlerini 0.85 olarak tespit etmiş̧tir.

Sonuç olarak Türkçe uyarlama çalışması yapılan PKTN'nin orijinal ölçekteki gibi altı faktörden oluştuğu, altı faktörlü modelin çalışmaya katılan genç sporculardan elde edilen verileri desteklediği, ölçeğin iç tutarlık katsayılarının yeterli düzeyde olduğu ve ölçeğin amacına hizmet ettiği anlaş̧lmıştır. Bu değerlendirmeler 1şı̆̆ında, araştırma sonucunda uyarlanan formun Türkiye'de özellikle genç sporcular seviyesinde antrenörleri ile ilgili pedagojik yeterlik algılarını belirleyebilecek olan geçerli ve güvenilir bir ölçme aracı olarak kullanılabileceği düşünülmektedir.

Sporda pedagojik yeterlik ile ilgili araştırmaların azlığı nedeniyle sporcuların kişisel farklılıkları konusunda kesin sonuçlar çıkarmak ve genellemeler yapmak güçtür. Bu sebeple araştırmada benzer kavramlar temel alınarak (antrenör liderliği, antrenör davranışı, antrenör sporcu ilişkisi, antrenör desteği) değerlendirmeler yapılmıştır. Analizler sonucunda genç sporcuların antrenörlerinin pedagojik yeterlikleri ile ilgili algılarında, empati ve dikkat, pozitif geri bildirim, sosyal destek ve hedef odaklı antrenman davranışlarında kadın sporcuların lehine anlamlı bir fark görülmüştür. Kadın sporcuların pedagojik yeterlik algılarının bu boyutlarda yüksek olması spor psikolojisi alanında tutum, algı üzerine yapılan çalışmaların, kadın sporcuların erkeklerden daha fazla psikolojik ağırlıklı destek beklentilerinin olduğu (Martin, Zakrajsek ve Wrisberg, 2012) yani kadın sporcuların erkek sporculardan farklı psikolojik ihtiyaçları olduğu (Chu, 2018; Steidinger, 2014) sonucuyla açıklanabilir. Bununla birlikte, antrenör-sporcu cinsiyeti uyumunu göz önünde bulunduran çalışmalar bu konularda cinsiyet farklılıklarını göstermektedir (Kavussanu ve diğ., 2008; Myers ve diğ., 2005). Araştırma bulgularımızı destekler nitelikte Villalon ve Martin (2020)'in lise antrenörlerinin etkinliğinde sporcuların cinsiyet farklılığını belirlemek için yaptığı araştırmada sadece kadın sporculara antrenörlük yapanların motivasyon ve fiziksel koşullandırma etkinliklerinin, hem erkek hem de kadın sporcuların antrenörlerine göre önemli düzeyde düşük düzeyde olduğunu, sadece erkek sporculara antrenörlük yapanlara göre ise fiziksel koşullandırma etkinliklerinin önemli düzeyde düşük düzeyde olduğunu belirtmiştir. Bu durum psikososyal ihtiyaçlar gibi diğer kaynaklardan da etkileniyor olabilir. Örneğin, algılanan desteğin kadın antrenörler için erkek antrenörlerden daha güçlü bir etkinlik kaynağı olduğu bilinmektedir (Myers ve diğ., 2005). Antrenörlerinin hedef odaklı antrenman davranışlarında kadın sporcuların erkek 
sporculara göre daha yüksek algılamalarının nedeni ise, bu tür bir davranışın daha otoriter algılanması ve kadın sporcuların otoriter davranışlara karşı daha hassas olmalarına bağlamak mümkün olabilir.

Sporcuların yaşlarına göre yapılan incelemede sporcuların yaşı arttıkça antrenörün empati ve dikkat, pozitif geri bildirim, sosyal destek, demokratik antrenman iklimi ve hedef odaklı antrenman yeterlik algısının azaldığı görülmüştür. Sporcuların yaşlarının artmasıyla beraber pedagojik yeterlik algısının düşmesi gelişim süreçlerindeki değişimle alakalı olabilir. Her şeyden önce sporcuların gelişim sürecinin yıllara göre farklık göstermesi, çevresel farklılıklar ve verilen desteğin değişkenlik göstermesi gibi nedenlerle her yaş dönemini birbirinden ayrıştırmaktadır. Araştırmalar (DurandBush ve Salmela 2002; Côté ve diğ., 2003) bu gelişim düzeyinin katılım dönemi, özelleşme dönemi ve gelişim dönemi olmak üzere üç ana aşamadan oluşan bir model üzerinde gerçekleştiğini belirtmiştir. Katılım yıllarında (6-12 yaş) çocuklar genellikle farklı sporlara katılırlar ve antrenörün temel rolü deneyimlerinin ağırlıklı olarak eğlenceli olmasını sağlamaktır. Antrenör tarafından sporcuların desteklendikleri, yönlendirildikleri, cesaretlendirildikleri ve teşvik edildikleri bir dönem olarak değerlendirilmektedir. Özelleşme yıllarında (13-15 yaş arası), çocuklar bir veya iki spor dalına odaklanırlar. Antrenör etkinlikleri eğlenceli ve heyecan verici hale getirir. Pratik yapmaları ve aynı zamanda atletik gelişimleri için de pozitif geri bildirim ve destekle yönlendirmesi gerekir. Son olarak, gelişim yıllarında (16 yaş +$)$, bireysel anlamda performansa önem veren, branş gelişimine yoğunlaşan sporcunun bir spor dalında veya seçtiği spor dalında üst düzey performans için adanmışlık düzeyi gösterdiği bir dönem olarak kabul edilmektedir. Gelişim dönemlerinde sporcular seçmiş olduğu ve kendilerini yetiştirdiği branşlarda daha uzun uğraşlara ve amaçlı antrenmana yer verirken; antrenörler sporcuların antrenman detaylarını, antrenman uygulamalarını ve yarışmalarını planlamak için çok zaman harcarlar. Bu bilgiler kullanılarak sporcunun yaşına bağlı olarak antrenörü ile ilgili pedagojik yeterlilik algısının daha küçük yaşlarda yüksek seviyelerde algılanması ile sonuçlanabilir. Ayrıca, sporcuların gelişimi ve yaşı ilerledikçe antrenörlerin kullandıkları pedagojik stratejiyi değiştirebileceği anlamına da gelebilir. Leith, (2006) yaş ve beceri seviyesi farklılıklarına göre antrenörlerin de rollerinin farklılaşacağını ve farklı antrenörlük davranışlarını yerine getirmesi gerektiğini belirtmiştir. Örneğin; çocuk ve gençler (ilkokul ve ortaokul dönemi), düşük konu yönelimli ve yüksek ilişki yönelimli antrenörü, 15-18 yaş grubu sporcular (lise dönemi) orta/düşük düzeyde konu yönelimli ve orta/yüksek düzeyde ilişki yönelimli antrenörü, 19-22 yaş grubu sporcular (üniversite dönemi) orta/yüksek düzeyde konu yönelimli ve orta/düşük düzeyde ilişki yönelimli antrenörü, yaşça büyük olan sporcular (profesyoneller) ise yüksek düzeyde konu yönelimli ve düşük düzeyde ilişki yönelimli antrenörü tercih edebilir. Araştırma bulgularımızla farklılık gösteren Weinberg ve Gould (2003) araştırmasında sporcuların yaşları ilerlediğinde ve sporcu olarak olgunlaştıklarında, artan düzeyde otoriter ve sosyal açıdan destekleyici antrenörleri tercih ettiklerini belirtmişlerdir. Ayrıca Morgan ve diğg., (2008)'ın İngiliz Premier Liginde 15 takımda üç farklı grupta (U12, U15 ve U18) antrenörlük yapan futbol antrenörleri üzerinde yaptığı araştırmada daha yaşlı oyuncularda (18 yaş altı) en sık kullanılan davranışın talimat ve geri bildirim olduğunu belirlenmiştir. Bunula beraber daha genç yaş gruplarında (12 yaş altı) dikkat ve sorgulama davranışlarının daha çok kullanıldığını belirlenmiştir. Araştırma bulgularımızı destekleyen Ford ve diğ., (2010)'ın üç farklı yaştaki (9, 13 ve 16 yaş) futbolcularda yaş ve yeteneklerinin bir fonksiyonu olarak antrenör davranışlarının ne ölçüde değiştirdiğini araştırmıştır. Araştırma sonucunda antrenörlük davranışının, yaşın bir fonksiyonu olarak değiştiğini belirlemiştir.

Son olarak sporcuların antrenörlerinin pedagojik yeterlikleri ile ilgili algılarında, empati ve dikkat, pozitif geri bildirim, sosyal destek, demokratik antrenman iklimi ve hedef odaklı antrenman davranışlarında kadın antrenörleri olan sporcuların lehine anlamlı bir fark görülmüştür. Sporcu-antrenör ilişkisi ile ilgili bazı çalışmalar, sporcuların erkek ve kadın antrenörlere yönelik duygularına incelemiş ve genellikle erkek bir antrenörün otokratik bir davranış sergilediğini, kadın antrenörlerin ise daha yadımsever bir davranış sergiledikleri belirtilmiştir (Vanden Auweele, 1999). Bununla 
Antrenör Pedagojik Yeterlik Ölçeğinin Türk Kültürüne Uyarlanması ve Genç Sporcuların Algılarına Göre Antrenörlerin

Pedagojik Yeterliklerinin İncelenmesi

Adaptation of Trainers' Pedagogical Competencies Scale to Turkish Culture and Examination of Trainers' Pedagogical

Competencies According to Perceptions of Young Athletes

beraber Fasting ve Pfister (2000) dört farklı ülkede elit kadın futbolcularla yaptığı nitel araştırmada antrenör yeterliliği konusunda kadın futbolcuların görüşlerine göre antrenörün cinsiyetinin herhangi bir farklılık göstermediğini bulunmuştur. Bununla birlikte, kadın oyuncular erkek antrenörlerin daha agresif olduğunu düşünürken, kadın antrenörlerin hem takım hem de bireysel iletişim açısından daha fazla empati sahibi oldukları belirlenmiştir. Ayrıca, bu oyuncuların bazıları erkek antrenörler tarafından çok fazla ciddiye alınmadıklarını belirtmişlerdir. Benzer şekilde, antrenörlük etkinliği ve antrenör cinsiyeti arasında tutarlı sonuçlar olmamasına rağmen, çoğunlukta cinsiyet farklılıkları bildirilmektedir (Kavussanu ve diğ., 2008; Lee ve diğ., 2002; Marback ve diğ., 2005). Araştırma bulgularını destekleyen Myers, ve diğ. (2005) yaptıkları çalışmada algılanan desteğin (sosyal) kadın antrenörler için erkek antrenörlerden daha güçlü bir etkinlik kaynağı olduğu bildirilmiştir. Araştırma bulgularımızla kısmen benzerlik gösteren Lacy ve Goldston (1990), kadın ve erkek jimnastik antrenörleri üzerinde gözlem yöntemi kullanarak yaptı̆̆ çalışmada antrenör davranışlarında küçük farklılıklar belirlemiştir. Eitzen ve Pratt (1989), kadın basketbol takımlarının hem erkek hem de kadın antrenörlerin antrenörlük felsefesindeki farklılıkları ortaya koymak için 250 kadın basketbolcu üzerinde yaptı̆̆ araştırmada beş koçluk felsefesi (antrenörün sporcuların genel gelişimindeki rolü, takım performansını maksimize etmek için gerekli olduğuna inanılan koşullar, kullanılan takım kuralları, spor özdeyişlerinin kullanımı ve sporcuların beklentileri) alanını araştırmışı̧ı. Araştırma sonucunda sporcuların genel gelişimindeki rolünde kadın antrenörler, sporcunun pozitif bir imaj yaratmasına yardımcı olmaya erkek antrenörlerden daha fazla önem verdiği bulunmuştur. Takım performansını maksimize etmek için gerekli olduğuna inanılan koşullar olan ikinci alanda kadın ve erkek antrenörlerin benzer koşullara değer verdikleri belirlenmiştir. Takım kurallarında ise, kadınlar antrenörlerin erkek antrenörlere göre maçtan önce hazırlık, performansa odaklanma, sportmenlik konularına daha önem verdikleri, erkek antrenörlerin ise dakiklik ve yasaklar konusunda daha duyarlı oldukları görülmüştür. Spor özdeyişleri ile ilgili var olan birkaç farkl1lıkta, ifadelere kadınlar antrenörler erkek antrenörlere göre daha büyük önem verdiği görülmüştür. Bu küçük farklılıkların olmasına rağmen antrenör cinsiyetinin önemli bir faktör olmadığını ortaya koymuş ve ayrıca erkek ve kadın sporcuların koçluklarındaki farklılıkların cinsiyetten ziyade kişilik ve öğretim tarzı farklılıklarından kaynaklandığını belirtmiştir. Cinsiyet farklılıklarının nedenleri ayrıca, spor dünyasındaki kadın bireylerin toplumsal görüşlerinden olumsuz etkilenen öz yeterlik ve özgüvenle ilgili olanlar gibi iç kökenlerden de kaynaklanabilir (Coakley, 2009). Araştırmada ortaya konulan destek veya dayanışmanın engellenmesinde ise erkek antrenörleri olan sporcuların lehine anlamlı bir fark görülmesi, antrenörlüğün erkek egemen bir iş olduğu ve erkek antrenörlerin daha otokratik olması nedeniyle olabilir. Ayrıca bu durum sporcuların psikososyal ihtiyaçlarını karşılamayla ilgili olabilir. Bazı kadın antrenörlerinin sporcularını başarılı bir şekilde destekleyebilmeyi ve motive etmeyi zor bulmasıyla (Chu, 2018; Steidinger, 2014) açıklanabilir. Benzer şekilde, sadece kadın sporculara antrenörlük yapan kadın antrenörler, hem erkek hem de kadın sporcu antrenörlerine göre motivasyon etkinliğini ve hedef odaklı koşullandırma etkinliğini önemli ölçüde düşük bulunmuştur. Sadece erkek sporculara antrenörlük eden kadınlara göre hedef odaklı koşullandırma etkinliği de önemli ölçüde düşürmüştür.

Yapılacak olan diğer çalışmalarda farklı illerdeki sporcular için ölçeğin geçerlik ve güvenirlik için yeniden incelenmesi ve örneklemin Türkiye'yi temsil edecek düzeyde artırılması önerilebilir. Araştırmanın diğer bir sınırlılı̆̆ ise antrenörlerin eğitim ya da pedagojik tutum, davranış veya yeterliklerini ölçebilen bir ölçme aracına rastlamamasından dolayı, farklı bir ölçek ile ilişkisine yönelik eş değer ölçek geçerliği yapılmamasıdır. Daha sonraki çalışmalarda bu ölçek ile pedagojik yeterlik kavramına uygun farklı bir ölçekle eş değer ölçek geçerliği yapılabilir. Ayrıca antrenör yeterlik algısının sporcuların ilişki, sosyalleşme gibi başka ölçekten elde edilen verilerin ilişkisel analizi yapılarak farklı modeller ortaya konulabilir. 


\section{KAYNAKLAR}

1. Alpar R. (2010). Spor, Să̆llk ve Eğitim Bilimlerinden Örneklerle Uygulamalı İstatistik ve Geçerlik-Güvenirlik. Ankara: Detay Yayıncılık.

2. Altıntaş A, Çetinkalp ZK, Aş̦ı FH. (2012). Evaluating the Coach-Athlete Relationship: Validity and Reliability Study. Spor Bilimleri Dergisi, 23(3), 119-128.

3. Baumann S. (2016). Psychologie im Jugendsport: Der Einfluss der Pubertät-Die Auswirkungen auf das Lernen-Die Rolle des Trainers. Aachen: Meyer \& Meyer Verlag.

4. Baumgartner H, Homburg C. (1996). Applications of structural equation modeling in marketing and consumer research: A review. International Journal of Research in Marketing, 13(2), 139-161

5. Beaton DE, Bombardier C, Guillemin F, Ferraz MB. (2000). Guidelines for the process of cross-cultural adaptation of self-report measures. Spine, 25(24), 3186-3191.

6. Bentler PM. (1980). Multivariate analysis with latent variables: Causal modeling. Annual review of psychology, 31(1), 419-456.

7. Bentler PM, Bonett DG. (1980). Significance tests and goodness of fit in the analysis of covariance structures. Psychological bulletin, 88(3), 588-606.

8. Berry JW, Lonner WJ. (1986). Field methods in cross-cultural research. California: Sage Publications, Inc.

9. Brislin R, Lonner W, Thorndike R. (1973). Cross-cultural Research Methods. New York: John Wiley.

10. Brown TA. (2015). Confirmatory factor analysis for applied research (2. ed.). New York: The Guilford Press.

11. Browne MW, Cudeck R. (1993). Alternative ways of assessing model fit. London; Sage focus editions.

12. Büyüköztürk S, Akgün ÖE, Özkahveci Ö, Demirel F. (2004). The validity and reliability study of the Turkish version of the motivated strategies for learning questionnaire. Educational Sciences: Theory \& Practice, 4(2), 232-237.

13. Büyüköztürk Ş. (2016). Sosyal bilimler için veri analizi el kitabl: İstatistik, araștırma deseni SPSS uygulamaları ve yorum. Ankara: Pegem A Yayincilik.

14. Chelladurai P. (1993). Handbook of research on sport psychology (Leadership In RN, Singer M, Murphy LK. Tennant, Eds.). New York: Macmillan Pub Co, 647-671

15. Chu TL. (2018). The Roles of Coaches, Peers, and Parents in High School Athletes' Motivational Processes: A Mixed-Method Study. Doctoral dissertation.

16. Coakley J. (2011). Youth sports: What counts as “positive development?". Journal of Sport and Social Issues, 35(3), 306-324.

17. Côté J, Baker J, Abernethy B. (2003). From Play to Practice. Expert Performance in Sports: Advances in Research on Sport Expertis. United State: Human Kinetics, 89-113.

18. Çokluk Ö, Şekercioğlu G, Büyüköztürk Ş. (2010). Multivariate Statistics for the Social Sciences: SPSS and LISREL Applications. Ankara: Pegem Akademi.

19. Davis LL. (1992). Instrument review: Getting the most from a panel of experts. Applied Nursing Research, 5(4), 194-197.

20. Durand-Bush N, Salmela JH. (2002). The development and maintenance of expert athletic performance: Perceptions of world and Olympic champions. Journal of Applied Sport Psychology, 14(3), 154-171

21. Ekenci MT, Yücel MG, Ekenci G. (2017). Antrenör-sporcu ilişkisi ölçeğinin Türkiye için geçerlilik ve güvenilirlik analizi. Akademik Sosyal Araștırmalar Dergisi, 5, 1-13.

22. Çelik HE, Yılmaz V. (2016). LISREL 9.1 ile Yapısal Eşitlik Modellemesi: Temel Kavramlar-Uygulamalar-Programlama. Ankara: An Yayıncilik.

23. Fasting K, Pfister G. (2000). Female and male coaches in the eyes of female elite soccer players. European Physical Education Review, 6(1), 91-110.

24. Filiz B, Demirhan G. (2017). Antrenörlük davranışı değerlendirme ölçeği’nin türk kültürüne uyarlanması. Spormetre Beden Eğitimi ve Spor Bilimleri Dergisi, 15(1), 1-10.

25. Ford PR, Yates I, Williams AM. (2010). An analysis of practice activities and instructional behaviours used by youth soccer coaches during practice: Exploring the link between science and application. Journal of Sports Sciences, 28(5), 483-495.

26. Güngörmüş HA, Gürbüz B, Yenel F. (2008). Spor için liderlik ölçeği’nin sporcuların antrenörün davranışlarını algılaması versiyonunun psikometrik özelliklerinin değerlendirilmesi. Atatürk Journal of Physical Education and Sport Sciences, 10(2), 16-21.

27. Hinde RA. (1997). Relationships: A Dialectical Perspective. Cambridge: Psychology Press.

28. Holt NL, Kingsley BC, Tink LN, Scherer J. (2011). Benefits and challenges associated with sport participation by children and parents from low-income families. Psychology of Sport and Exercise, 12(5), 490-499.

29. Hu LT, Bentler PM. (1998). Fit indices in covariance structure modeling: sensitivity to underparameterized model misspecification. Psychological Methods, 3(4), 424-453.

30. Jowett S, Cockerill IM. (2002). Incompatibility in the coach-athlete relationship. Solutions in Sport psychology, 16-31.

31. Kavussanu M, Stamp R, Slade G, Ring C. (2009). Observed prosocial and antisocial behaviors in male and female soccer players. Journal of Applied Sport Psychology, 21(S1), S62-S76.

32. Kline RB. (2016). Mean structures and latent growth models. Principles and practice of structural equation modeling, (4th ed). New York: The Guildford Press, 369-393.

33. Kline RB. (2015). Principles and Practice of Structural Equation Modeling. New York: Guilford publications.

34. Kline, T. J. (2005). Psychological Testing: A Practical Approach To Design And Evaluation. Thousand Oaks, CA: SAGE Publications, Inc.

35. Krüger A. (1989). Trainer brauchen Pädagogik. Leistungssport, 19(5), 31-33.

36. Kurz D, Sack HG, Brinkhoff KP. (1996). Materialien zum Sport in Nordrhein-Westfalen: Kindheit, Jugend Und Sport İn NordrheinWestfalen: Der Sportverein Und Seine Leistungen. Düsseldorf.

37. Lacy AC, Goldston PD. (1990). Behavior analysis of male and female coaches in high school girls' basketball. Journal of Sport Behavior, 13(1), 29

38. Lee KS, Malete L, Feltz DL. (2002). The strength of coaching efficacy between certified and noncertified singapore coaches. International Journal of Applied Sports Sciences, 14(1).

39. Leith LM. (2006). The Psychology Of Coaching Team Sports: A Self-Help Guide. Toronto: Sport Books Publisher.

40. Marback TL, Short SE, Short MW, Sullivan PJ. (2005). Coaching confidence: An exploratory investigation of sources and gender differences. Journal of Sport Behavior, 28(1), 18

41. Martin SB, Zakrajsek RA, Wrisberg CA. (2012). Attitudes toward sport psychology and seeking assistance: Key factors and a proposed model. Psychology of Attitudes, 1-33.

42. Morgan G, Spray CM, Harwood CG. (2008). Coaching behaviours within academies and centres of excellence: A focus on the use of feedback and questioning. FA Insight, Summer, 28-33.

43. Myers ND, Vargas-Tonsing TM, Feltz DL. (2005). Coaching efficacy in intercollegiate coaches: Sources, coaching behavior, and team variables. Psychology of Sport and Exercise, 6(1), 129-143. 
Antrenör Pedagojik Yeterlik Ölçeğinin Türk Kültürüne Uyarlanması ve Genç Sporcuların Algılarına Göre Antrenörlerin Pedagojik Yeterliklerinin İncelenmesi

Adaptation of Trainers' Pedagogical Competencies Scale to Turkish Culture and Examination of Trainers' Pedagogical Competencies According to Perceptions of Young Athletes

44. Pawlenka C. (2004). Ethik für Training und Wettkampf im Sport. Prohl, R. \& Lange, H. Pädagogik des Leistungssports. Schorndorf: Hofmann, 93-114.

45. Pratt SR, Eitzen DS. (1989). Contrasting leadership styles and organizational effectiveness: The case of athletic teams. Social Science Quarterly, 70(2), 311.

46. Riemer HA, Chelladurai P. (1998). Development of the athlete satisfaction questionnaire (ASQ). Journal of Sport and Exercise Psychology, 20(2), 127-156.

47. Schermelleh-Engel K, Moosbrugger H, Müller, H. (2003). Evaluating the fit of structural equation models: Tests of significance and descriptive goodness-of-fit measures. Methods of Psychological Research Online, 8(2), 23-74.

48. Seçer İ. (2015). SPSS ve LISREL ile Pratik Veri Analizi: Analiz ve Raporlaştırma. Ankara: Anı Yayıncılık.

49. Selağzı, S., \& Çepikkurt, F. (2015). Antrenör ve sporcu iletişim düzeylerinin belirlenmesi. CBÜ Beden Ĕ̆itimi ve Spor Bilimleri Dergisi, 9(1), 11-18.

50. Smoll FL, Smith RE. (1989). Leadership behaviors in sport: a theoretical model and research paradigm 1. Journal of Applied Social Psychology, 19(18), 1522-1551.

51. Steidinger J. (2014). Sisterhood In Sports: How Female Athletes Collaborate And Compete. Lanham, Maryland: Rowman \& Littlefield.

52. Sümer N. (2000). Yapısal eșitlik modelleri: Temel kavramlar ve örnek uygulamalar. Türk psikoloji yazıları, 3(6), 49-74.

53. Tinning R. (2012). The idea of physical education: A memetic perspective. Physical Education \& Sport Pedagogy, 17(2), 115-126.

54. Toros T, Tiryaki Ş. (2006). Sporda liderlik ölçeği'nin-futbolcuların antrenör davranışlarını algılaması versiyonunun-geçerlik ve güvenirlik çalışması. Uluslararası Spor Bilimleri Kongresi, Muğla.

55. Unutmaz V, Gençer RT. (2014). Spor için liderlik ölçeği-sporcunun antrenör davranışını algılaması versiyonunun psikometrik özelliklerinin incelenmesi. CBÜ Beden Eğitimi ve Spor Bilimleri Dergisi, 7(1), 27-34

56. Vanden Auweele Y. (1999). Parents-coach interpersonal relationships. Motricidade Humana-Portugese Journal of Human Performance Studies, 12(1), 77-88.

57. Varga D, Földesi G, Gombocz J. (2018). Declared pedagogical values of coaches at hungarian football academies. Physical Culture and Sport. Studies and Research, 77(1), 17-24.

58. Villalon CA, Martin SB. (2020). High school coaches' coaching efficacy: relationship with sport psychology exposure and gender factors. Journal of Applied Sport Psychology, 32(1), 64-80

59. Weinberg RS, Gould D. (2003). Foundations of Sport And Exercise Psychology. Human Kinetics.

60. Zetter H. (2008). Zur Pädagogischen Kompetenz von Trainern und Trainerinnen im Nachwuchsleistungssport. Doctoral dissertation, uniwien

\section{Ek: PKTN model değerlerİ}

\begin{tabular}{|c|c|c|c|}
\hline $\begin{array}{l}\text { Faktörler/Maddeler } \\
\text { Benim antrenörüm, }\end{array}$ & $\begin{array}{l}\text { Standart } \\
\text { yükler }\end{array}$ & t-değeri & $\mathbf{R}^{2}$ \\
\hline \multicolumn{4}{|l|}{ Empati ve Dikkat(ED) } \\
\hline ED1: ... antrenmanın benim için iyi gitmediğini anlar ve bana moral verir & 0.69 & 15.96 & 0.47 \\
\hline ED2: ... beni takım ile ilgili sorunlar üzerinde konuşmaya motive eder & 0.71 & 16.69 & 0.50 \\
\hline ED3: ... önemli maçlarda bizimde fikrimizi sorar & 0.55 & 12.19 & 0.30 \\
\hline ED4: ... benim için örmek bir modeldir & 0.59 & 13.16 & 0.35 \\
\hline ED5: ... bir maçtan sonra nasıl hissettiğimi anladığını gösterir & 0.72 & 16.95 & 0.51 \\
\hline ED6: ... önemli bir maçta istenilen performansı yerine getirmediğim zaman beni teselli eder & 0.69 & 16.15 & 0.48 \\
\hline \multicolumn{4}{|l|}{ Destek veya Dayanışmanın Engellenmesi (DDE) } \\
\hline DDE1: ... bir oyunda yenilgiye uğradığımız zaman çok sinirleniyor & 0.51 & 10.87 & 0.27 \\
\hline $\begin{array}{l}\text { DDE2: ... antrenmanlarda tüm sporcular tarafından konun ne olduğunun anlaşılmasına dikkat } \\
\text { eder* }\end{array}$ & 0.55 & 11.64 & 0.30 \\
\hline DDE3: ... açılklamalarda yeterince net değildir & 0.49 & 10.30 & 0.24 \\
\hline DDE4: ... üzerimde baskı uygular & 0.79 & 18.57 & 0.62 \\
\hline DDE5: ... bireysel performansa önem verir* & 0.73 & 16.58 & 0.53 \\
\hline DDE6: ... başarısızlıkta tüm suçu biz oyunculara yükler & 0.66 & 14.78 & 0.44 \\
\hline DDE7: ... sorularımızı ve yorumlarımızı duymazlıktan gelir & 0.27 & 5.38 & 0.07 \\
\hline DDE8: ... talimatları ile beni bunaltır & 0.37 & 7.48 & 0.14 \\
\hline \multicolumn{4}{|l|}{ Pozitif Geri Bildirim (PGB) } \\
\hline PGB1: ... iyi bir performans gösterdiğimde mutlu olduğunu belli ediyor & 0.51 & 10.31 & 0.26 \\
\hline PGB2: ... oyundan sonra bana neyin üzerinde çalışmam gerektiğini söyler & 0.61 & 12.32 & 0.37 \\
\hline PGB3: ... antrenman içerisinde gösterdiğim iyi performansı över & 0.52 & 10.57 & 0.27 \\
\hline \multicolumn{4}{|l|}{ Sosyal Destek (SD) } \\
\hline SD1: ... okul sorunlarını dikkate alır & 0.57 & 11.96 & 0.32 \\
\hline SD2: ... evde sorunlarım varsa ailem ile konuşur & 0.68 & 14.85 & 0.46 \\
\hline SD3: ... antrenman dişında da oyuncular ve takım ile zaman geçirir & 0.63 & 13.50 & 0.40 \\
\hline SD4: ... onunla özel konularımı rahatlıkla konuşmama izin verir & 0.61 & 13.00 & 0.37 \\
\hline \multicolumn{4}{|l|}{ Demokratik Antrenman İklimi (DAİ) } \\
\hline DA1: ...yaptı̆̆ımız eleştirileri ve önerilerimizi dikkate alır & 0.59 & 12.75 & 0.35 \\
\hline DA2: ... antrenmanlarla ilgili konularda bize de karar hakk1 verir & 0.50 & 10.67 & 0.25 \\
\hline DA3: ... antrenman için önerilerde bulunmamız için bizi motive eder & 0.74 & 16.51 & 0.55 \\
\hline \multicolumn{4}{|l|}{ Hedef Odaklı Antrenman (HOA) } \\
\hline BOYS1: ... antrenman içerisinde sıkı bir disiplin sağlar & 0.54 & 10.29 & 0.26 \\
\hline BOYS2: ... oyundan sonra performansımızı eleştirir & 0.62 & 12.55 & 0.38 \\
\hline BOYS3: ...her şeyden önce iyi bir lig konumuna sahip olunmasına dikkat eder & 0.44 & 8.83 & 0.19 \\
\hline
\end{tabular}

*İlgili alt boyutta maddeler test kodlanmıştır. 